\title{
The Contributing Role of the Green Marketing Dimensions in Supporting the Blue Ocean Strategy Principles: An Exploratory Study of the Opinions of a Sample of Managers in Altameem Diary Plant
}

\author{
Wijdan H. Hamoody ${ }^{1}$, Hiba M. Hussein ${ }^{2}$ \\ \{e-mail: wijdanhassan@ntu.edu.iq, hiba_mohammed@ntu.edu.iq \\ Department of Business Management Techniques, Technical College of Management, Northern Technical \\ University Mosul, Iraq ${ }^{1,2}$
}

\begin{abstract}
The study elucidate the contributing role of the green marketing dimensions in supporting the blue ocean strategy which supporting and strengthening the competitive advantage of organizations to meet the current competitive environment and sustainability. Organizations can produce environmentally friendly products while simultaneously avoiding severe competition by using a blue ocean strategy. This helps the organization achieve the objectives of higher returns, added value, competitive advantage, positive reputation of being an organization that meets the needs of stakeholders and simultaneously protects the environment. The relationship between the green marketing dimensions and the blue ocean strategy principles was tested and results in data are analysis by The questionnaire were distributed among employees in manager-level positions. The results show that there are a significant correlation and effect between the two variables of the study and lead to the conclusion that a significant correlation and impact of the green marketing dimensions in supporting the blue ocean strategy.
\end{abstract}

Keywords: Green Marketing, Blue Ocean Strategy

\section{Introduction}

Environmental concern among organizations began to emerge remarkably in the late fifties and early sixties of the last century as a result of a number of factors such as governmental pressure and growing awareness of business groups and researchers in this field. Management approaches in line with this trend emerged in attempts to find appropriate solutions and methods aiming at protecting the natural environment and its components. One of these approaches is the green marketing approach which underwent a series of developments to finally take a clear shape in the early nineties. Green marketing is considered an integrated systematic process aimed at attracting customers to eco-friendly products while taking into account achieving a competitive advantage in rapid and highly competitive markets.

Organizations may choose to devise a blue ocean strategy in order to avoid struggling in highly competitive markets, gain a market share free from bloody competition, and enter an uncontested market through differentiation and building new forms of demand. The blue ocean strategy is a term used for a strategy that avoids severing completive markets that are analogous to bloodied waters. Instead, it aims at capturing new market opportunities not previously known by competitors and thus achieving excellence and disengaging from the competition at the same time.

The study consists of four main sections. The first section includes the research methodology. The second section covered the theoretical aspect of both the green marketing dimensions and 
the blue ocean strategy. The third section discusses the results from the field part of the study that took place in the Altameem Dairy Plant in Nineveh Governorate. The last section concludes the study with a number of conclusions and recommendations.

\section{Methodology.}

\subsection{Problem Statement}

Due to growing environmental awareness and limited natural environmental resources, organizations have increased their interest in moving towards sustainability while facing constant pressures to provide a solution to meet the objectives of the organization without harming the environment. One of such solutions is by following a green marketing policy while avoiding, through the blue ocean strategy, conflict with competing organizations. Thus, the problem of study can be expressed through the following questions:

1. Does the management of the investigated organization have a clear idea of the variables of study represented by the green marketing dimensions and the blue ocean strategy principles?

2. Is there a significant correlation and impact between the variables of study?

3. Do green marketing dimensions contribute to the blue ocean strategy principles?

\subsection{The Importance of the Study.}

The importance of the study stems from its use of a theoretical and practical framework to shed light on how much green marketing dimensions support the blue ocean strategy principles in the investigated company. These green marketing dimensions include; eliminating the concept of waste, reinventing the concept of the product, clarifying the relationship between price and cost, and making environmental orientation profitable.

\subsection{The Objectives of the Study.}

The study attempt to achieve the following objectives

1. Understand the role played by the green marketing dimensions in supporting the blue ocean strategy principles.

2. Identify the range of the relationship between the green marketing dimensions and achieving the blue ocean strategy principles.

\subsection{The hypotheses of the study.}

The study included two main hypotheses:

The First main hypothesis: There is a significant correlation between the green marketing dimensions (collectively and individually) and the blue ocean strategy principles.

The second main hypothesis: There is a significant impact of the green marketing dimensions (collectively and individually) on the blue ocean strategy principles.

\subsection{The Model of the Study}

The methodological treatment of the problem of the study and its hypotheses required building a hypothetical model as follows in Figure 1: 


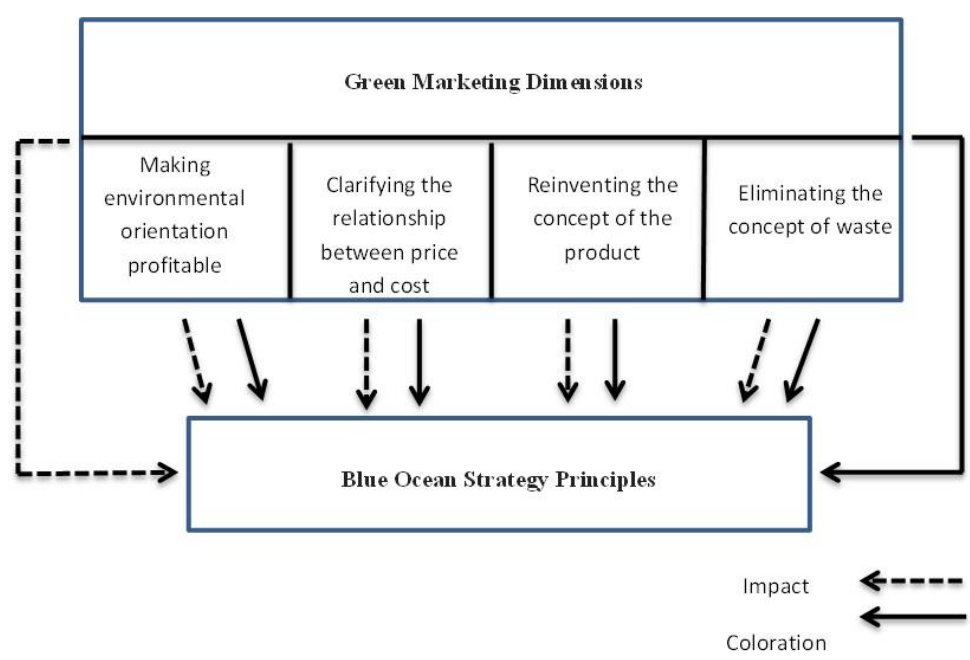

\subsection{Data Acquisition.}

Fig.1. The Model of the study

In order to present a theoretical framework for the subject of the study, the researchers resorted to a number of Arabic and foreign sources in literature, doctoral and master dissertations and thesis related to the subject of research, publications on the world wide web and the Internet, and the field study. A questionnaire was used to test the study's hypotheses. The questionnaire was based on a five-point Likert scale and it included two parts as shown in the appendix. The first part of the questionnaire covered the green marketing dimensions as the independent variable of the study and included (15) items. The second part was dedicated to the blue ocean strategy principles as the dependent variable and included (10) items. The questionnaire form was distributed among a sample of (23) employees in the positions of the unit, department, and division manager in the Altameem Diary Plant in Ninevah/Iraq and the response rate was $(100 \%)$.

\subsection{Data Analysis Tools.}

The researchers relied on a number of statistical tools for the purpose of arriving at the results of the statistical analysis by using the statistical SPSS package. The statistical tools included percentage, arithmetic mean, standard deviation, simple correlation in determining the strength of the relationship between the variables, and simple regression analysis to determine the significance of the impact of the independent variable on the dependent variable.

\section{Theoretical Background}

\subsection{Green Marketing.}

The Concept of Green Marketing: Green marketing and its philosophy are considered an integrated marketing view that aims at creating a positive impact on customer preferences in a way that motivates the customers towards demanding environmentally friendly products. Researchers and authors in the field of management in general, and marketing in particular, have developed several concepts of green marketing. Green marketing was defined by Henion \& 
Kinneri 1976 [1] as the study of the positive and negative aspects of marketing activities and their environmental footprint, while Stanton 1997 [2] refer to it as a marketing activity of a specific company which aims to create a positive or eliminate a negative impact of a certain product on the environment. The authors in Dauympie \& Pason 2000 [3] refer to green marketing as a creative management approach aimed at achieving a balance between the needs of customers, the requirements of the environment, and the goal of profitability and Albakri, 2006 [4] added that it is a process of developing, pricing, and promoting products that do not harm the natural environment. The term was defined by Najm 2008 [5] as the process of marketing or promoting products based on their environmental performance. Thus, it is concluded that green marketing is one of the activities necessary for the sustainability of the organization in a green environment. It is a marketing process that is not different from any marketing process in general, but it cares more about the environment.

The Importance of Green Marketing: The importance of green marketing based on the agreement of a number of authors [6,4] can be stated as follows:

1- Improving the reputation of the organization: The organization's reputation reflects its interaction with its stakeholders including owners, customers, suppliers, employees, banks and NGOs. Adopting the philosophy of green marketing makes the organization close to its customers, especially those with environmental orientations. Such companies receive strong support from all constitutes of the community because of the alignment between its objectives and the community's objectives regarding environmental commitment. The support received by the organization from its community helps it strengthen its relationship with its current and future customers. The organization adopting the green market philosophy produces high-quality products, uses trustworthy advertising, and acts in a social and environmentally responsible manner giving it a good reputation in the market. This good reputation helps the organization in its marketing efforts by utilizing marketing opportunities and influencing responsible consumer behavior which leads to increased sales and high market value of its shares, increasing in its value and its attractiveness to investors Fig. 2 [6].

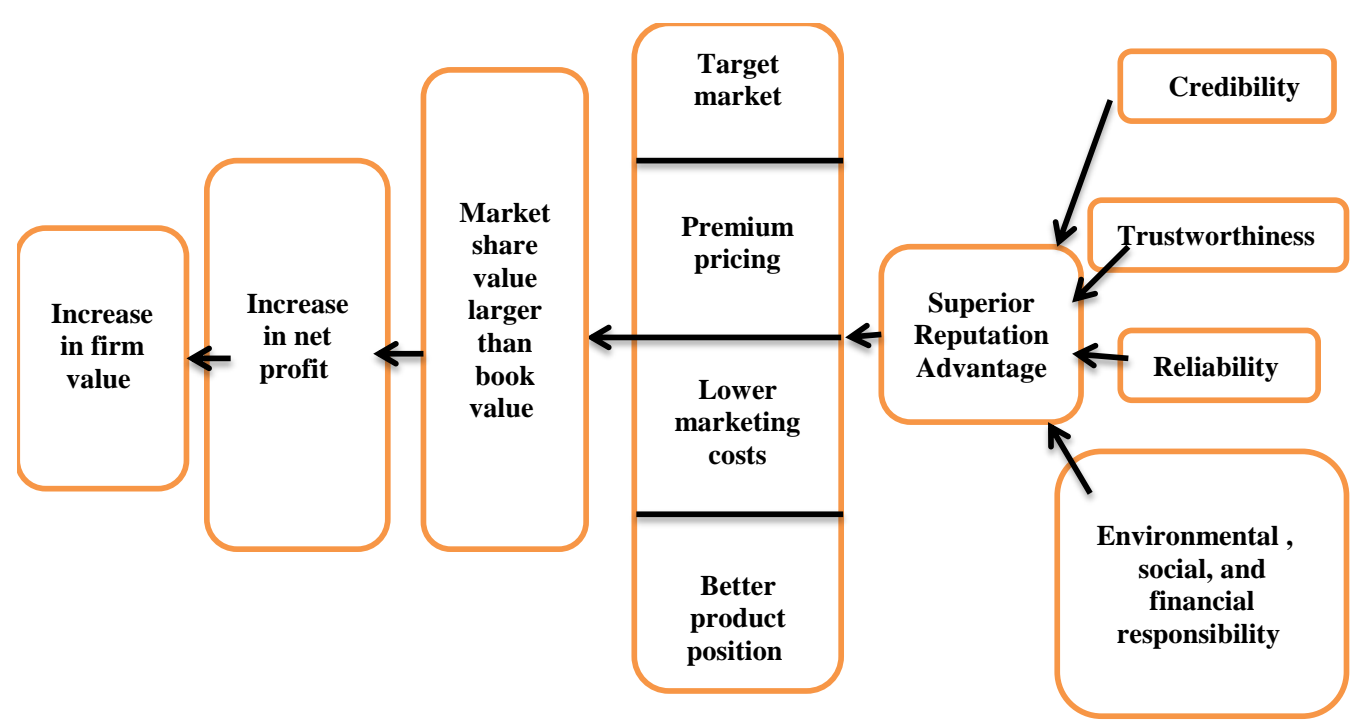

Fig. 2. The relationship between the organization's good reputation and its marketing and financial performance. 
2- Achieving a Competitive Advantage: Green marketing is expected to open new horizons and attractive market opportunities for organizations, allowing them to avoid traditional competition, and thereby, gain a competitive advantage in the market. The competitive advantage in such a case is achieved by creating specific environmental values for customers and thus creating eco-friendly market sectors putting the organization ahead of its competitors in the market from an environmental point of view.

3. Profiting: The use of high-efficiency production methods that rely on efficient use of raw materials, recycling or energy-saving, would help organizations achieve savings in cost and more profits.

4. Increasing the market share: In the face of increasing environmental problems, customer loyalty to the traditional market brands will decline over time and customers will turn to ecofriendly products and packaging. Therefore, this is considered an opportunity for organizations that adopt green marketing to increase their market share.

5. Ensure the safety of product delivery and operations management: This is done by always seeking to provide the best for green customers by focusing on the production of safe and ecofriendly products by increasing the efficiency of production processes while reducing the levels of environmental damage and pollution resulting from production processes.

6. Maintaining Activities: Green organizations avoid legal prosecution and gain support from their community because of their acceptable objectives and philosophy and therefore, they become more capable of sustaining their activities in providing eco-friendly products and support their operations and marketing activities.

7. Personal Incentives: Green marketing offers opportunities and incentives for managers to follow modern and effective methods in providing eco-friendly products. This bestows on them a feeling of personal contribution to environment protection.

From the aforementioned points, we can conclude that the importance of green marketing lies in guiding the organization's efforts in marketing environmentally friendly products with the goal of achieving higher profits and returns in addition to competitive advantage and a good reputation in meeting the stakeholder's needs.

Measures and Requirements of Green Marketing: When contemplating adopting a green marketing philosophy successfully, the organization must undertake a set of measures as illustrated by [7] and may include:

1. Extensively studying current environmental issues in the organization.

2. Systematically measuring and monitoring the environmental impacts of the organization's performance.

3. Setting a clear and realistic environmental policy parallel with the objectives and programs of the organization.

4. Using appropriate means to train and qualify employees based on environmental orientation.

5. Performing scientific research to address environmental problems and technology use.

6. Developing educational programs to educate consumers and raise their awareness of environmental responsibility and their support for environmental programs and efforts.

7.Using appropriate means to qualify the organization's suppliers based on the environmental orientation of the organization.

8. Participating in the establishment and support of social initiatives concerned with the environment and society.

Green marketing dimensions: Implementing a green marketing strategy can be possible when a number of dimensions are present. The dimensions often stated and which are agreed upon by a number of authors $[8,9,10,4]$ include: 
1- Eliminating the concept of waste: The traditional concept of dealing with industrial waste has changed in green marketing. Focus is increasingly directed towards designing and producing goods with minimum or zero waste instead of disposing of waste after production. The question changed from (What should we do with waste?) to (How to produce goods without waste?)

2- Reinventing the concept of the product: This means that production technology must conform to the concept of environmental commitment. Production must depend largely on eco-friendly raw materials, the use of raw material must be minimum, and products should be recycled at the end of their life to be reused in production. This requires designing products to be reassembled and reused within a closed life cycle. Packaging must also rely on eco- friendly and recyclable raw material.

3- Clarifying the relationship between price and cost: The price of the product must reflect its real cost or close to it. This means that the price of the commodity (the real cost to the consumer) must equal the value obtained from the commodity including the added value of making the product green.

4- Making the environmental orientation profitable: Many organizations have recognized that green marketing is a market opportunity that may give them a potentially sustainable competitive advantage. In fact, most traditional organizations compete in the market for quick profits regardless of the negative effects on the environment. On the other hand, organizations that monitor the competitive landscape may find that green marketing is a strategic competitive outlet that can take the organization to another level of competition especially after the growing environmental awareness among consumers and their gradual transformation into green consumers. The main advantage of this strategic approach is that it can benefit from the activities of official and non-official organizations that promote environmental sound orientations through various media channels. This can be considered free advertisement and support for organizations that adopt the green marketing approach and it is considered profitable, especially in the long term. The aforementioned statements confirm the feasibility of green marketing because of the rise in consumer awareness of the threats in the marketing environment.

\subsection{The Blue Ocean Strategy.}

The blue ocean concept: Before discussing the blue ocean strategy concept, it is worth clearing the term blue ocean in management. Blue ocean denotes an unknown market space, untainted by competition in contrast to red-colored markets characterized bloody competition. The blue ocean strategy is a relatively modern strategic term in management literature. The term originated in the western countries resulting from modern developments in strategic management reflecting the evolving world of business and a result of serious and long-term research. The credit goes to the authors [11] for presenting this modern competitive and marketing strategy. The new strategic approach is based on creating an undisputed market space far from cutthroat competition. Competition becomes irrelevant to the organization using the blue ocean strategy as it increases the demand for its products while it disengages from the competition. In the same context [12] indicates that a blue ocean market represents undiscovered markets and industries where there is no demand for their products yet and are free from strong competition. Blue oceans require the creation of value and innovation and are confined to adding value. The authors [13] describe the analogy of blue ocean markets to pristine blue oceans not tainted with red stains caused by the bloody competition and this is one of the secrets that make companies design their logos and brand with varying degrees of blue shades. As for the blue ocean strategy, many writers and researchers have defined it as a new way of innovative management aiming at opening up new markets by inventing new methods and systems to 
maximize management efficiency and thus generate more profits [14]. The blue ocean strategy is described by [15] as a strategy to create new value for the organization by breaking the differentiation-cost tradeoff and create new market space. It is about pursuing differentiation and low cost simultaneously in a sense that gives the organization a competitive advantage. The concept of blue ocean strategy is summarized by [16] as anything within this frame that gives the organization an advantage over the rest of the competitors.

Thus, the blue ocean strategy concept can be defined as a strategy formulated in an uncontested environment, free from competitive struggle. In this environment, the organization is able to differentiate itself in a superior marketing position.

The Blue Ocean Strategy Dimensions: The main objective of the blue ocean strategy is to demarcate new market boundaries to disengage from the competition and create a blue ocean market through a number of blue ocean strategy dimensions which can be described as follows $[17,11]$ :

1. Monitoring organizations with similar or substitute products/services: An organization that seeks differentiation should have a comprehensive view by carefully examining and monitoring the activity of their peers producing similar or substitute goods /services.

2. Transition through strategic conglomerates: Some organizations only monitor competitors operating within the same industry or those with similar strategies. Firms working the car industry paying no attention to what other locomotive industries produce as they are considered non-competitors. Such a narrow view must be overcome in order to find a blue ocean market.

3. Re-defining the target customer segment: All organizations in an industry target a specific consumer segment. In the pharmaceutical industry, the focus is largely on the influencing decision-makers such as doctors while ignoring the common sense of focusing on the users of their products.

4. Monitoring of complementary goods and services: Some value is usually discovered in complementary goods and services that are the solutions sought by consumers when choosing a product or service. Success opportunities may lay in the complimentary service more than in the product itself.

5. Reconsidering the organization's functional and emotional marketing approaches: Competition between organizations differ in a number of aspects. Some focus on the costbenefit calculations and others compete by stirring customers' emotional responses. However, the attractiveness of most goods is rarely in its essence one of the two. When organizations seek to dominate the market, they should seek to consolidate these two models.

6. The perspective of time: those interested in the changes that occur over time can see a considerable change in the demand and consumption patterns resulting from the spread of environmental awareness and the global movements to protect the environment. This represents a real opportunity to create a new market by determining the impact of these shifts on changes in the customer's value and the activities of the organization when setting a clear course for future activity.

The Blue Ocean Strategy Principles: The principles underlying the blue ocean strategy formulation according to[18,16,11] can be stated as follows:

1. Reconstructing market boundaries: This principle identifies the paths by which the organization can find a new market and break free from competition by creating an uncontested market space across diverse industry domains, hence decreasing search risk and making it possible for the organization to move towards the blue ocean strategy.

2. Focusing on the big picture: The process of strategic planning by focusing on the big picture is the key to reducing planning risk by focusing on the objectives and discovering available blue 
ocean opportunities. This helps organizations explore its future strategy and communicate it in a comprehensive way that leads to effective implementation.

3. Reaching Beyond Existing Demand: The organization adopting a blue ocean strategy must challenge its conventional practices. Instead of narrowly focusing on its customers, it should focus on its stakeholders. Instead of segmentation to meet existing customer preferences, which results in small target markets, the organization should focus on the commonalities across a large number of market segments and design products to meet the needs of this newly created market.

4. Getting the strategic sequence right.: Organizations seeking change and development in their area of activity seek to correctly implement the blue ocean strategy. The blue ocean strategy building criteria are based on consumer utility, price, and target cost. Strategies based on this sequence helps to achieve the desired goals and to employ experiences to reach the requirements of consumers.

5. Overcoming key organizational hurdles: Every implementation of the Blue Ocean strategy faces four obstacles [11]:

- Cognitive: Waking employees up to the need for a strategic shift and a change in the status quo.

- Limited Resources: Individuals in the organization must agree on a new strategic plan and provide sufficient resources to make changes and momentum.

- Motivation: Implementing a blue ocean strategy successfully requires explaining the need to change because turning the strategy into dynamic action requires individuals that understand what needs to be done and to act accordingly.

- Politics: Politics is one of the administrative concepts that guide the organization's decision-makers, controls the implementation of work, contribute to the organization of internal and external relations, and motivates individuals to make a strong move forward towards change.

6. Build execution into strategy: Management should create trust and commitment in individuals and respect their views and proposals while it should inspire their voluntary cooperation to do their best. This will help the organization reduce its risks and implement a successful strategy.

\section{Results and Discussion.}

This section identifies and describes the research variables based on the hypothetical model of the study, as well as elucidating the correlation and impact between the two variables.

\subsection{Identification and Description of study variables}

4.1.1. Green marketing dimensions: Table 1. shows the data that describes the independent variable which consisted of the green marketing dimensions. The first green marketing dimension showed the highest percentage of agreement of (100\%) in the variable (X4) with an arithmetic mean of (4.782) and a standard deviation of (0.421), while it showed the lowest percentage of agreement of $(91.3 \%)$ in the variable (X3) with an arithmetic mean of (4.608) and a standard deviation of (0.572). The second dimension showed the highest percentage of agreement of (95.7\%) in the variable (X5) with an arithmetic mean of (4.652) and a standard deviation of (0.572). The third dimension showed the highest percentage of agreement of $(91.3 \%)$ in the variable (X11) with an arithmetic mean of (4.434) and a standard deviation of (0.787), while it showed the lowest percentage of agreement of $(73.9 \%)$ in the variable (X10) with an arithmetic mean of (4.260) and a standard deviation of (1.053). The fourth dimension showed the highest percentage of agreement of (95.6\%) in the variable (X12) with an arithmetic mean of (4.739) and a standard deviation of (0.688). 
Table 1. Identification and description of study variables (Independent variable)

\begin{tabular}{|c|c|c|c|c|c|c|c|c|c|c|c|c|}
\hline \multicolumn{13}{|c|}{ Green Marketing Dimensions } \\
\hline \multirow[t]{2}{*}{ variable } & \multicolumn{2}{|c|}{$\begin{array}{l}\text { I do not } \\
\text { agree } \\
\text { strongly }\end{array}$} & \multicolumn{2}{|c|}{$\begin{array}{l}\text { I do not } \\
\text { agree }\end{array}$} & \multicolumn{2}{|c|}{$\begin{array}{c}\text { Neutral } \\
\text { agreed }\end{array}$} & \multicolumn{2}{|c|}{ agreed } & \multicolumn{2}{|c|}{$\begin{array}{l}\text { Strongly } \\
\text { agreed }\end{array}$} & \multirow[t]{2}{*}{$\begin{array}{c}\text { Arithmetic } \\
\text { mean }\end{array}$} & \multirow[t]{2}{*}{$\begin{array}{l}\text { standard } \\
\text { deviation }\end{array}$} \\
\hline & No. & $\%$ & No. & $\%$ & No. & $\%$ & No. & $\%$ & No. & $\%$ & & \\
\hline $\mathrm{X} 1$ & - & - & - & - & 1 & 4.3 & 2 & 8.7 & 20 & 87.0 & 4.826 & .491 \\
\hline $\mathrm{X} 2$ & - & - & - & - & 1 & 4.3 & 3 & 13.0 & 19 & 82.6 & 4.826 & .387 \\
\hline $\mathrm{X} 3$ & - & - & 1 & 4.3 & 1 & 4.3 & 4 & 17.4 & 17 & 73.9 & 4.608 & .782 \\
\hline $\mathrm{X} 4$ & - & - & - & - & - & - & 5 & 21.7 & 18 & 78.3 & 4.782 & .421 \\
\hline X5 & - & - & - & - & 1 & 4.3 & 6 & 26.1 & 16 & 69.6 & 4.652 & .572 \\
\hline X6 & - & - & - & - & - & - & 5 & 21.7 & 16 & 69.6 & 4.608 & .656 \\
\hline X7 & - & - & 4 & 17.4 & 3 & 13.0 & 3 & 13.0 & 13 & 56.5 & 4.087 & 1.202 \\
\hline X8 & - & - & - & - & 4 & 17.4 & 3 & 13.0 & 16 & 69.6 & 4.521 & .790 \\
\hline X9 & - & - & 1 & 4.3 & 4 & 17.4 & 4 & 17.4 & 14 & 60.9 & 4.347 & .934 \\
\hline X10 & - & - & 2 & 8.7 & 4 & 17.4 & 3 & 13.0 & 14 & 60.9 & 4.260 & 1.053 \\
\hline X11 & - & - & 1 & 4.3 & 1 & 4.3 & 8 & 34.8 & 13 & 56.5 & 4.434 & .787 \\
\hline X12 & - & - & 1 & 4.3 & - & - & 3 & 13.0 & 19 & 82.6 & 4.739 & .688 \\
\hline X13 & - & - & 3 & 13.0 & 2 & 8.7 & 1 & 4.3 & 17 & 73.9 & 4.478 & .994 \\
\hline X14 & - & - & 1 & 4.3 & 1 & 4.3 & 3 & 13.0 & 18 & 78.3 & 4.652 & .775 \\
\hline X15 & 1 & 4.3 & - & - & 3 & 13.0 & 2 & 8.7 & 17 & 73.9 & 4.478 & 1.038 \\
\hline
\end{tabular}

4.1.2 Blue ocean strategy principles: Table 2. shows the data that describe the independent variable, which consisted of the blue ocean strategy principles and shows it achieved the highest percentage of agreement of $(95.6 \%)$ for the variable (X21) with a mean of (4.608) and a standard deviation of $(0.583)$ and the lowest agreement was $(78.3 \%)$ for the variable (X12) with a mean of (4.434) and a standard deviation of (0.895).

Table 2. Identification and description of study variables (dependent variable)

\begin{tabular}{lcccccccccccc}
\hline & \multicolumn{10}{c}{ Blue Ocean Strategy Principles } \\
\hline variable & $\begin{array}{c}\text { I do not } \\
\text { agree } \\
\text { strongly }\end{array}$ & $\begin{array}{c}\text { I do not } \\
\text { agree }\end{array}$ & $\begin{array}{c}\text { Neutral } \\
\text { agreed }\end{array}$ & agreed & $\begin{array}{c}\text { Strongly } \\
\text { agreed }\end{array}$ & $\begin{array}{c}\text { Arithmetic } \\
\text { mean }\end{array}$ & $\begin{array}{c}\text { standard } \\
\text { deviation }\end{array}$ \\
\cline { 2 - 10 } & No. & $\%$ & No. & $\%$ & No. & $\%$ & No. & $\%$ & No. & $\%$ & & \\
\hline X16 & - & - & - & - & 2 & 4.3 & 7 & 30.4 & 14 & 60.9 & 4.521 & .665 \\
X17 & - & - & 4 & 17.4 & - & - & 9 & 8.7 & 17 & 73.9 & 4.565 & .895 \\
X18 & - & - & - & - & 3 & 13.0 & 6 & 26.1 & 14 & 60.9 & 4.478 & .730 \\
X19 & - & - & 1 & 4.3 & 3 & 13.0 & 4 & 17.4 & 14 & 60.9 & 4.434 & .895 \\
X20 & - & - & 1 & 4.3 & 2 & 4.3 & 6 & 26.1 & 14 & 60.9 & 4.434 & .843 \\
X21 & - & - & - & - & 1 & 4.3 & 7 & 30.4 & 15 & 65.2 & 4.608 & .538 \\
X22 & - & - & - & - & 3 & 13.0 & 3 & 13.0 & 17 & 73.9 & 4.565 & .662 \\
X23 & - & - & - & - & 3 & 13.0 & 3 & 13.0 & 17 & 73.9 & 4.608 & .722 \\
\hline
\end{tabular}

\subsection{Analysis of correlation and impact between search variables.}

This analysis aims at verifying the validity of the research hypotheses and their significance. 4.2.1.The correlation between the green marketing dimensions and the blue ocean strategy principles: Table 3 . indicates that there is a positive correlation between green marketing and 
its dimensions (collectively and individually) and the blue ocean strategy principles. The correlation of the total index was $(0.858 * *)$ which is significant at the level of $(0.01)$. The table also shows a positive and significant correlation between each of the dimensions of green marketing and the blue ocean strategy principles. The third dimension (clarifying the relationship between price and cost) scored a value of (0.806), indicating a large role in supporting these principles in the investigated diary plant, followed by the fourth dimension (making environmental orientation profitable) with a score of (0.799), while the second and third dimensions followed respectively in their correlation scores. Thus, the first main hypothesis is accepted.

Table 3. The correlation between green marketing dimensions and the blue ocean strategy principles.

\begin{tabular}{|c|c|c|c|c|c|}
\hline & \multicolumn{3}{|c|}{ Green Marketing Dimensions( Independent } & \multirow[b]{2}{*}{$\begin{array}{c}\text { Variable) } \\
\text { Making } \\
\text { environmental } \\
\text { orientation } \\
\text { profitable }\end{array}$} & \multirow[b]{2}{*}{$\begin{array}{c}\text { Overall } \\
\text { Index }\end{array}$} \\
\hline & $\begin{array}{c}\text { Eliminating } \\
\text { the concept of } \\
\text { waste }\end{array}$ & $\begin{array}{l}\text { Reinventing } \\
\text { the concept of } \\
\text { the product }\end{array}$ & $\begin{array}{l}\text { Clarifying the } \\
\text { relationship } \\
\text { between price } \\
\text { and cost }\end{array}$ & & \\
\hline $\begin{array}{l}\text { Blue Ocean } \\
\text { Strategy } \\
\text { Principles } \\
\text { (Dependent } \\
\text { Variable) } \\
\end{array}$ & $0.592 *$ & $0.643^{*}$ & $0.806 * *$ & $0.799 * *$ & $0.858^{*}$ \\
\hline
\end{tabular}

4.2.2. The relationship of the impact of the green marketing dimensions on the blue ocean strategy principles: The results of the regression analysis indicate that there is a significant impact of green marketing dimensions and the blue ocean strategy principles as shown in Table 4. The calculated value of $(\mathrm{F})$ reached (58.499) which is greater than its table value of (4.324) at two degrees of freedom (1 and 21). The value of the coefficient of determination $\left(R^{2}\right)$ was (0.736) indicating that $(73 \%)$ of the variation in the dependent variable (blue ocean principles) reflects the variation in the independent variable. The value of the calculated (T) was (7.648) at a level of significance of (0.05) which is larger than its table value of (1.714) and thus validating the second main hypothesis that hypothesized a significant impact of the green marketing dimensions on the blue ocean strategy principles

Table 4. The impact relationship of the green marketing dimensions on the blue ocean strategy principles

\begin{tabular}{|c|c|c|c|c|c|c|}
\hline \multirow{3}{*}{$\begin{array}{c}\text { Blue Ocean } \\
\text { Strategy Principles } \\
\text { (Dependent } \\
\text { Variable) }\end{array}$} & \multicolumn{2}{|c|}{$\begin{array}{l}\text { Green Marketing Dimensions } \\
\text { (Independent Variable) }\end{array}$} & \multirow[t]{2}{*}{ R2 } & \multirow[t]{2}{*}{$\mathrm{t}$} & \multicolumn{2}{|l|}{$\mathrm{F}$} \\
\hline & $\beta 0$ & $\beta 1$ & & & Calculated & Tabular \\
\hline & 0.925 & 0.858 & 0.736 & 7.648 & 58.499 & 4.324 \\
\hline
\end{tabular}

As for the relationship of the impact of the green marketing variables on the blue ocean strategy principles, Table 5. shows the value of the coefficient of determination $\left(\mathrm{R}^{2}\right)$ indicates that $(79 \%)$ of the variance in the independent variable (the green marketing dimensions) impacts the 
dependent variable (the blue ocean strategy principles). As the calculated (T) value of (2.048) is larger than its table value of (1.717) at a significance level of (0.05), and the calculated( F) value of (17.625) is greater than its table value (3.127), then the second main hypothesis is accepted.

Table 5. The impact relationship of the green marketing variables on the blue ocean strategy principles.

\begin{tabular}{|c|c|c|c|c|c|c|c|c|}
\hline & \multicolumn{5}{|c|}{$\begin{array}{l}\text { Green Marketing Dimensions (Independent } \\
\text { Variable) }\end{array}$} & \multirow[t]{2}{*}{$\mathrm{R}^{2}$} & \multicolumn{2}{|c|}{$\mathrm{F}$} \\
\hline & $\beta 0$ & $\beta 1$ & $\beta 2$ & $\beta 3$ & $\beta 4$ & & Calculated & Tabular \\
\hline $\begin{array}{c}\text { Blue Ocean Strategy } \\
\text { Principles (Dependent } \\
\text { Variable) }\end{array}$ & $\begin{array}{c}0.311 \\
(2.048)\end{array}$ & 0.063 & 0.345 & 0.186 & 0.43 & 0.797 & 17.625 & 3.127 \\
\hline
\end{tabular}

\section{Conclusions and Recommendations. \\ 5.1 Conclusions:}

1. To follow a green marketing policy, the investigated diary plant should seek to meet the demands of its customers while taking into consideration the protection of the environment through the green marketing dimensions including; eliminating the concept of waste, reinventing the concept of the product, clarifying the relationship between price and cost, and making environmental orientation profitable, in a way that ensures sustainability.

2. To implement the blue ocean strategy the investigated diary plant should follow its strategy principles including; reconstructing market boundaries to overcome the competition, focusing on the big picture, overcoming key organizational hurdles, and building execution into strategy. This is to help it acquire a unique competitive advantage free from competition.

3 . The results of the analysis of correlation revealed a significant correlation between the green marketing dimensions and blue ocean strategy principles in terms of the components of the independent variable. This confirms the important role of green marketing dimensions in supporting the blue ocean strategy principles.

4. We conclude from the results of the analysis of the impact that there is a significant impact of green marketing dimensions on the blue ocean strategy principles that derive their supporting elements from the green marketing dimensions.

\subsection{Recommendations:}

In light of previous conclusions, the researchers propose a set of recommendations as follows: 1. The investigated diary plant should understand the importance of green marketing dimensions and blue ocean strategy principles, especially in the context of shifting towards environmental sustainability. This requires paying more attention to these dimensions and their impact on several important aspects that directly affect the momentum of organizations and their growth and survival in a competitive environment.

2. It is necessary that the investigated diary plant supports the workers with training and courses in order to increase their skills and experience in meeting the green marketing and blue ocean requirements of satisfying the needs of customers while protecting the environment. 
3. The investigated diary plant should overcome the hurdles encountering the implementation of the green marketing dimensions while taking into consideration the principles of blue ocean strategy, as they both play a prominent role in enhancing the competitive position and help avoid competitive struggling through producing green products.

Acknowledgments: Authors would like to give special thanks for the Department of Business Management Techniques, Technical College of Management, Northern Technical University, Mosul, Iraq for their support. We also thanks Dr. Thanoon Y. Thanoon the Dean of College Technical college of Management for his support.

\section{Refrences}

[1] Henion, K.E. and Kinnear, T.C. Ecological Marketing. American Marketing Association, Chicago.pp.3 (1976)

[2] Stanton, W.: Marteting, ,11 their win Mc Graw-Hill. pp. 612 (1997)

[3] Dauympie D., Parson L.: Marketing management, $7^{\text {th }}$ ed, john mile yand sons.pp. 19 (2000)

[4] Albakri, A.: Green market. Basic and modren concept, Dar aleazori scientific publisher, Amman, Jourden.pp.252(2006).

[5] Najem, N. A.:The Green Dimension of Business, Al-Warraq Foundation, Amman, Jordan. pp. 237 (2008)

[6] Miles M. P., Covin, J. G.: Environmental Marketing a source of Reputational Competitive and Advantage Journal Business Ethics, vol 23. pp. 28(2000)

[7] Kotler, P.: Marketing and its Evolution: Ethical Strategic Responsibility, Part I, 1, translated by Mazen Naqaa, Alaeddin Publications, Damascus. (2002)

[8] Tiwari, S., Tripathi D. M., Srivastava U., Yadav P.K.:Green marketing- Emerging Dimension. Journal of Business Excellence. Vol. 2, Issue 1, , PP-18-23 (2011)

[9] www.shodhganga.inflibuet.ac.in/bitstream/10603/132627/10/10_chapter\%202.pdf

[10] Al-Samadi, S.: Green Marketing - Obstacles in the Arab Organization, Arab Organization for Administrative Development of the 5th Arab Forum in Green Marketing, Beirut. (2006)

[11] Kim \& Mauboargne , R.: Creating new marked space, Harvard Business Review. (2006)

[12] Aldoori, Z. M. and ALsaedi, Y. A.: Analysis of the Blue Ocean Strategic Strategy within the Green Marketing Philosophy, 9th International Scientific Conference, Al Zaytoonah University, Amman, Jordan. (2009)

[13] Altalib , A. \& Albann, Z. : blue ocean strategy and sustainable competitive advantage. Dar Hamed For Publishing \& Distribution, Amman, Jordan. 1st edition . (2012)

[14] Pinal, S.:"LG Electronics the Blue ocean strategy "IBSCDC, India www.ibscdc.org. (2006)

[15] Boxter M. \& Lynn F.B.:Manging perform mince Improvement ront ledge.(2008)

[16] Mohamed, Z. A.: Analysis of the use of the blue ocean strategy ,case study Analysis Different Agencies Research Bulletin of the faculty of Economic and Managements Upm.4 march .http:llecom.upm.edy my research bulleting articles. (2009)

[17]Raouf, R. A.: The Role of Blue Ocean Strategy Dimensions in Marketing Performance, A Survey Study on the General Company for the Manufacture of Pharmaceuticals and Medical 
Supplies, Nineveh, Rafidain Development Journal, Volume 32, No. 98, Mosul University. (2010)

[18] Hamoody , W . H.:Role of Blue Ocean Strategy in Supporting Customer Relationship Management Tasks, Survey Study at National Furniture Manufacturing Company in Mosul.

Future Research Journal, Al-Hadba University College.( 2013) 